\title{
Effect of Reaction Conditions on the Particle Properties for Synthesis of Stabilized Zirconia by Modified Oxalate Method
}

\author{
Hyun-wook Park****, Young Jin Lee*, Jin-Ho Kim*, Dae-Woo Jeon*, \\ Hae Jin Hwang**, and Mi Jai Lee ${ }^{*, \dagger}$ \\ *Korea Institute of Ceramic Engineering and Technology, Optic and Display Material Center, Jinju 52851, Korea \\ **Department of Materials science and Engineering, Inha University, Incheon 22212, Korea \\ (Received June 7, 2016; Revised July 6, August 1, 2016; Accepted August 23, 2016)
}

\begin{abstract}
Nanocrystalline powder of zirconia stabilized with $8 \mathrm{~mol} \%$ yttria (YSZ) has been synthesized through oxalate process using $\mathrm{ZrOCl}_{2} \cdot 8 \mathrm{H}_{2} \mathrm{O}$ and $\mathrm{Y}\left(\mathrm{NO}_{3}\right)_{3} \cdot 6 \mathrm{H}_{2} \mathrm{O}$ as starting materials. Understanding of the characteristic changes of YSZ powder as a function of processing conditions is crucial in developing dense and porous microstructures required for fuel cell applications. In this research, microstructure change, surface area, particle shape and particle size were measured as a function of different processing conditions such as calcination temperature, stirring speed and concentration of starting materials. The resultant crystallite sizes were calculated by XRD-LB (X-Ray Diffraction Line-Broadening) method, BET method, and morphology of the crystal was observed in TEM and FE-SEM. The TEM examination showed that the powder synthesized with $0.7 \mathrm{M}$ of YSZ concentration had a spherical morphology with sizes ranging from 20 to $40 \mathrm{~nm}$. However, the powder was gradually aggregated above $1.0 \mathrm{M}$ of YSZ concentration with the aggregation being intensified as the YSZ concentration was increased.
\end{abstract}

Key words : Yttria stabilized zirconia, Oxalate method, Wet process, Aggregation

\section{Introduction}

$\mathrm{Z}$ irconia-based ceramics are being used for applications to not only industrial structural ceramics areas such as heat shield, but also electrical and electronic materials areas such as SOFC (Soild Oxide Fuel Cell) electrolyte, catalyst, dental material, $\mathrm{PZT}\left(\mathrm{PbZrTiO}_{3}\right.$, piezoelectric ceramic), etc. due to such desirable characteristics as thermal stability, chemical stability, excellent mechanical characteristics, and ionic conductivity. ${ }^{1-6)}$ Also, studies on nano powders are being extensively conducted, as densification can be achieved at lower temperatures than the existing temperatures, and mechanical characteristics as well as electrical conductivities become more excellent, raising expectation for applications in diversified industrial areas, upon starting from nano powders.

Synthesis of zirconia has been studied by diversified methods. Since general solid-state synthesis methods undergoing mechanical pulverization and mixing require a high temperature above $750^{\circ} \mathrm{C}$ at least and inhomogeneity of mixed powders can affect single-phase synthesis at a high temperature, powders in the present study were synthesized by using oxalate co-precipitation method as one of the wet chemical synthesis methods. The oxalate method

'Corresponding author : Mi Jai Lee

E-mail : im1004@kicet.re.kr

Tel : +82-55-792-2482, Fax : +82-55-792-2490 involves preparation of powders by undergoing processes where the oxalate obtained from co-precipitation reaction between metal ions and oxalic acid ions by complete dissolution of each raw material powder and oxalic acid is calcined and pulverized. This preparation method enables homogeneous mixing of cations in oxalic acid solution on an atomic level, facilitating synthesis of multi-component powders as well as addition of dopants. ${ }^{7-11)}$ As compared with other solution methods, the decomposition temperature of oxalate is particularly low, making it an effective method for obtaining fine and accurate composition ratios and improving homogeneity at relatively low temperatures. Also, as no byproducts are produced, there are advantages that formation of solid solutions is possible at a low temperature and pulverization of calcined powders is easy so that fine powders with excellent sinterability can be prepared. ${ }^{7-11)}$ However, problems still exist where there are many process control elements in comparison with general co-precipitation methods, and strong agglomerates can be formed in the heat treatment process for primary particles with a high reactivity. Such problems can be solved by controlling particle sizes and aggregation of fine powders in oxalic acid coprecipitation, where reaction conditions such as concentration or synthesis temperature of precursors are known particularly as the important variables. ${ }^{10)}$ Therefore, in the present study, particle size of synthesis products and form of aggregation upon preparation of stabilized zirconia using oxalate co-precipitation have been observed as a function of process control elements such as temperature per process, 
concentration of starting solution and stirring speed, etc.

\section{Experimental Procedure}

\subsection{Synthesis using Modified oxalate method}

As the starting raw materials for synthesis of stabilized zirconia powder, $\mathrm{ZrOCl}_{2} \cdot 8 \mathrm{H}_{2} \mathrm{O}(98 \%)$ and $\mathrm{Y}\left(\mathrm{NO}_{3}\right)_{3} \cdot 6 \mathrm{H}_{2} \mathrm{O}(99.99 \%)$ were used together with $\mathrm{C}_{2} \mathrm{H}_{2} \mathrm{O}_{4} \cdot 2 \mathrm{H}_{2} \mathrm{O}(>99.5 \%)$ and $\mathrm{NH}_{4} \mathrm{OH}$ aqueous solution as precipitants. $\mathrm{ZrOCl}_{2} \cdot 8 \mathrm{H}_{2} \mathrm{O}$ and 8 mole\% $\mathrm{Y}\left(\mathrm{NO}_{3}\right)_{3} \cdot 6 \mathrm{H}_{2} \mathrm{O}$ were dissolved in distilled water to prepare for the concentrations of $0.3 \mathrm{M}, 0.5 \mathrm{M}, 0.7 \mathrm{M}, 1.0 \mathrm{M}$, $1.5 \mathrm{M}, 2.0 \mathrm{M}$, and $2.5 \mathrm{M}$. These aqueous solutions were respectively placed in $5 \mathrm{~L}$ flasks for low-speed stirring, followed by dropping of the oxalic acid solution at a rate of 10 $\mathrm{ml} / \mathrm{min}$ in the form of drop by drop by using a burette. The oxalic acid solution was made to have 1.4 times of the metal ion concentration, and the $\mathrm{pH}$ was controlled to be 8 by using ammonia water. Reaction time upon synthesis was maintained at $4 \mathrm{~h}$, and synthesis temperatures were experimented under 3 conditions of 40,60 and $80^{\circ} \mathrm{C}$. Stirring was implemented for $12 \mathrm{~h}$ to ensure occurrence of sufficient precipitation reaction, and the co-precipitates were aged for 7 $\mathrm{h}$, filtered with distilled water, and washed for sufficient removal of $\mathrm{Cl}$ ions. The filtered precipitates were then dried and calcined for $4 \mathrm{~h}$, followed by wet milling using ethanol as a solvent.

\subsection{Characteristics evaluation}

To check for crystallinity of the calcined samples, diffraction patterns were examined by using an X-ray Diffractometer (Rigaku, DMAX-2500/PC). Measurement conditions for the diffraction angles in the range of $10 \sim 80^{\circ}$ included the scanning rate of $5 \% \mathrm{~min}$, the acceleration voltage of $40 \mathrm{kv}$, and the acceleration current of $200 \mathrm{~mA}$. To calculate the primary particle sizes using XRD peaks, the following DebyeScherrer equation was used:

\section{$\mathrm{D}=\mathrm{K} \lambda / \beta \cos \theta$}

where $\mathrm{D}$ is the calculated crystallize size, and $\mathrm{K}$ of 0.94 showing the Scherrer constant for a cubic structure. $\lambda$ the $\mathrm{X}$ ray wavelength, $\beta$ the half width for (111) face of XRD peak, and $\theta$ the Bragg angle. To observe particle size, form and distribution of powder as well as form of aggregation, a transmission electron microscope (JEOL, JEM4010) and a FE-SEM (JEOL, JSM-6700F) were employed, while particle size distribution was measured by using a Laser scattering particle size distribution analyzer (HORIBA, LA-950V2). Lastly, specific surface area values were measured by using BET (Micromeritics, ASAP2420) method, and the following equation was employed for calculation of the particle sizes by using the specific surface area values.

$$
\mathrm{B}_{\text {mean }}=6 \times 10^{3} / \rho \times \mathrm{SA}
$$

where SA shows the calculated specific surface area value, and $\rho$ the density the density $8 \mathrm{YSZ}$ (8 mol\% Ytrria-stabilized zirconia) with the value of $5.9 \mathrm{~g} / \mathrm{cm}^{3}$ being used

\section{Results and Discussion}

\subsection{Particles as a function of starting solution con- centrations}

To consider the primary particle sizes of zirconia powder as a function of the change in concentrations of precursor solution, the precipitates synthesized by dissolving in distilled water for the individual concentrations of $0.3 \mathrm{M}, 0.5$ $\mathrm{M}, 1.0 \mathrm{M}, 1.5 \mathrm{M}, 2.0 \mathrm{M}$, and $2.5 \mathrm{M}$ were calcined at $800^{\circ} \mathrm{C}$, and their microstructures observed through FE-SEM and TEM are shown in Fig. 1 and Fig. 2, respectively. While zirconia particles prepared at concentrations of $0.5 \mathrm{M}$ and 0.7 $\mathrm{M}$ as shown in Fig. 2 can be observed to exist as small particles of $20 \sim 40 \mathrm{~nm}$ in size with a spherical form, multitudes of large and angular-shaped particles due to aggregation among primary particles are observed with an increase in concentrations. At the concentration of $2.0 \mathrm{M}$, fine particles with a spherical form can be seen to almost disappear due to such aggregation. When the aggregation growth model is incorporated in the present experimental results, the amounts of produced zirconia particles are also increased at an increased concentration of reactants because of this. As the high concentration of zirconia in the solution eventually increases the aggregated amounts of particles, the mean size of particles will be thereby increased. Also, non-uniform sizes of the primary particles at a high concentration will

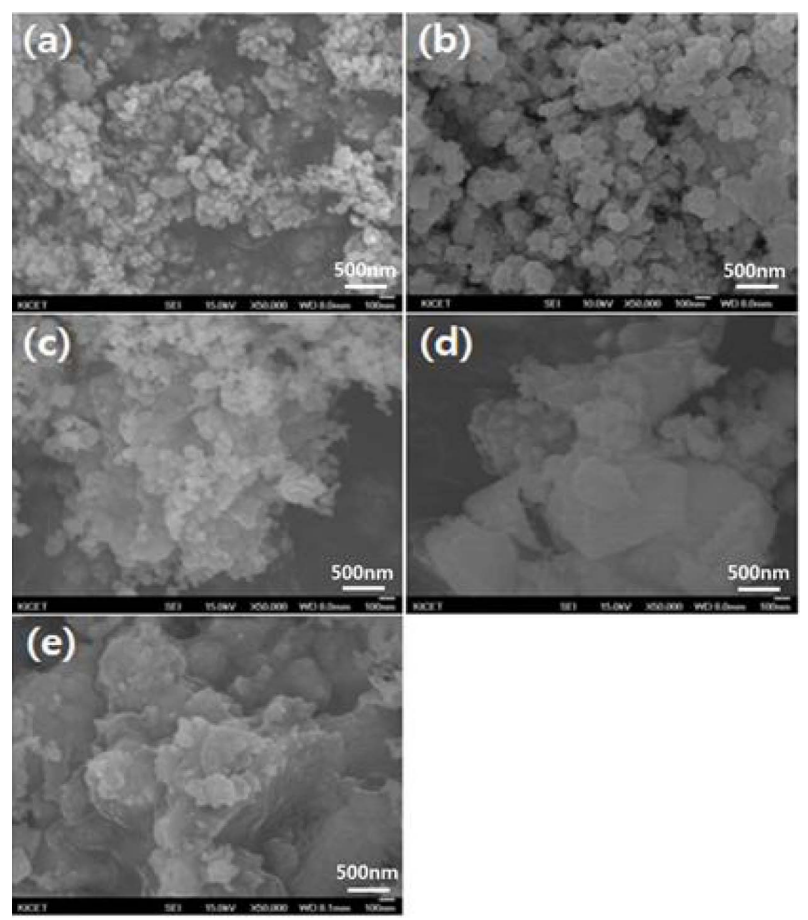

Fig. 1. FE-SEM images of the YSZ powders as a function of concentration of starting materials: (a) $0.5 \mathrm{M}$, (b) $0.7 \mathrm{M}$, (c) $1.0 \mathrm{M}$, (d) $1.5 \mathrm{M}$ and (e) $2.0 \mathrm{M}$. 


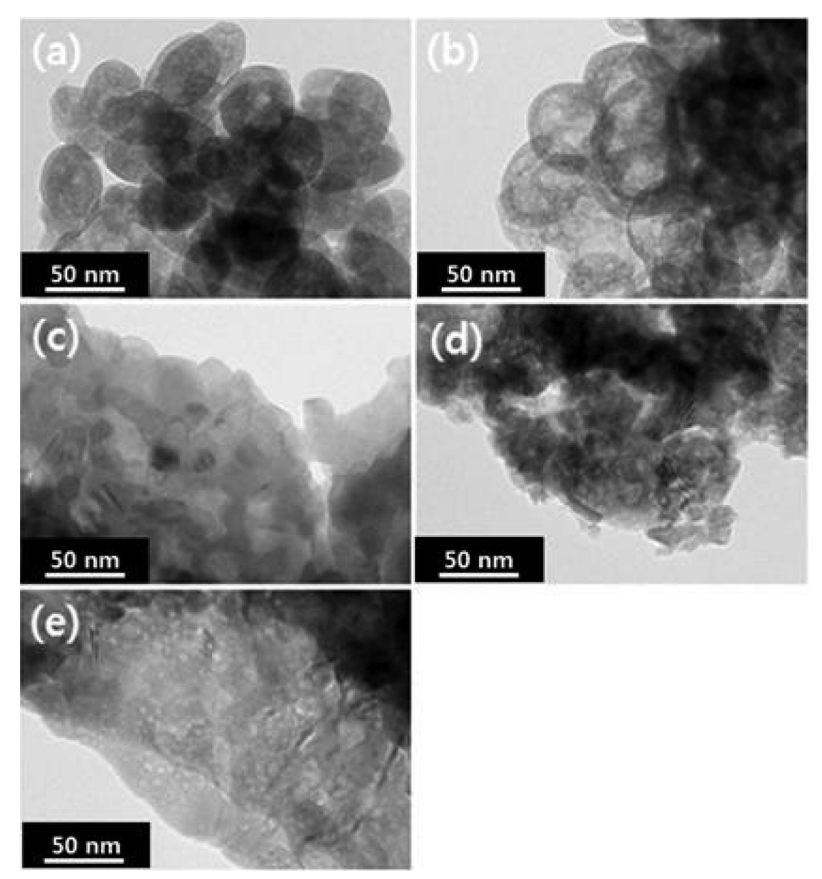

Fig. 2. TEM images of the YSZ powders as a function of concentration of starting materials: (a) $0.5 \mathrm{M}$, (b) $0.7 \mathrm{M}$, (c) $1.0 \mathrm{M}$, (d) $1.5 \mathrm{M}$ and (e) $2.0 \mathrm{M}$.

promote particle growth. For particles with different particle sizes, surface diffusion occurs faster on the smaller particles, due to which the small particles are subordinated to larger particles with the larger particles continuing to grow, thus causing abnormal particle growth. However, with the relatively uniform primary particles as at a low concentration, mutual surface diffusion rates are similar so as to cause relative slowdown of the growth rates. ${ }^{12)}$ Such interparticle aggregation can also be affirmed through the change in specific surface areas as a function of concentration as shown in Fig. 3. Specific surface areas were shown to be $24.2 \mathrm{~m}^{2} / \mathrm{g}$ at $0.3 \mathrm{M}$, and $8.0 \mathrm{~m}^{2} / \mathrm{g}$ at the highest concentration of $2.5 \mathrm{M}$. According to the results of specific surface area, drastic lowering of specific surface area values can also be affirmed to occur at the concentration of $1.0 \mathrm{M}$ as observed in the pictures of TEM and FE-SEM. Since the characteristics of zirconia started with nano powders have a considerably close correlation with aggregation, control of the aggregation through concentration control in the synthesis process is essential. ${ }^{13)}$

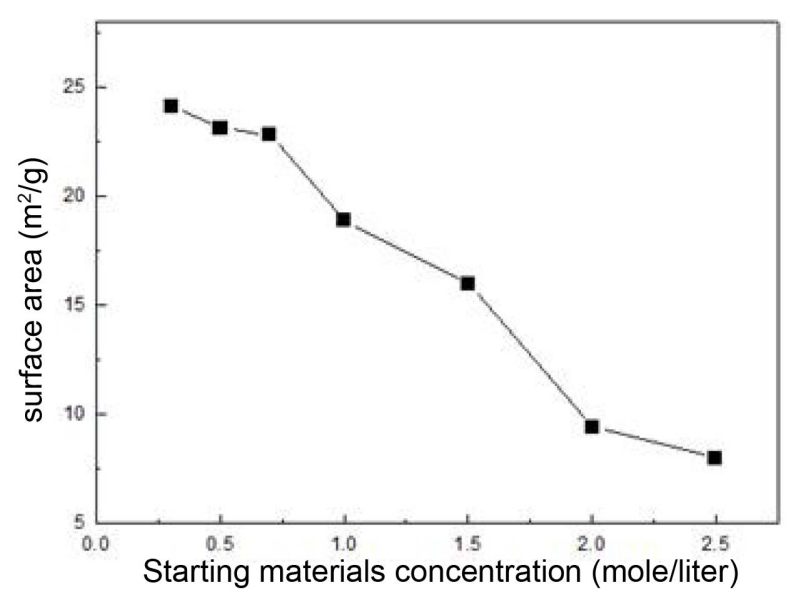

Fig. 3. Surface area of the YSZ powders as a function of concentration of the starting materials.

In Table 1, particle sizes as a function of starting solution concentrations are summarized through 3 types of methods such as th value calculated by using XRD-LB (X-Ray Diffraction Line Broadening) method, the mean value of particle size observed in TEM, and the value calculated through BET method. In all of these methods, an increase in the particle sizes with an increase in the concentrations can be affirmed, and the particle size showed values ranging from $27 \mathrm{~nm}$ to $127 \mathrm{~nm}$ under the condition of concentration change from $0.3 \mathrm{M}$ to $2.5 \mathrm{M}$, depending on measurement methods.

\subsection{Particles as a function of stirring speed}

Upon co-precipitation by oxalate method, particle size and aggregation has a close correlation with stirring speeds. In Fig. 4, analysis results of particle size upon synthesis are shown for the synthesized powder as a function of stirring speed, and gradual size reduction of the particles after drying, after calcination at $800^{\circ} \mathrm{C}$ and $1000^{\circ} \mathrm{C}$ can be affirmed with an increase in the stirring speeds. When the primary particles of stabilized zirconia are produced, the particles will grow by aggregation. Aggregation occurs due to attractive forces between particles, with inter-particle aggregation being caused by van der Waals force. ${ }^{14)}$ When the stirring speed is increased in the synthesis process, attactive forces between powders are reduced, interfering with aggregation due to reduction in the particle interaction potential. Also, when the stirring speed is increased, colli-

Table 1. Mean Particle Size of the 8YSZ Powders Obtained from Change of Concentration of Starting Materials Measured by Different Techniques

\begin{tabular}{cccccccc}
\hline Measurement(concentration) & $0.3 \mathrm{M}$ & $0.5 \mathrm{M}$ & $0.7 \mathrm{M}$ & $1.0 \mathrm{M}$ & $1.5 \mathrm{M}$ & $2.0 \mathrm{M}$ & $2.5 \mathrm{M}$ \\
\hline $\mathrm{D}(\mathrm{nm})$ & 27 & 34 & 38 & 59 & 64 & 76 & 79 \\
$\mathrm{~T}_{\text {mean }} \operatorname{size}(\mathrm{nm})$ & 30 & 33 & 37 & - & - & - & 108 \\
$\mathrm{~B}_{\text {mean }} \operatorname{size}(\mathrm{nm})$ & 42 & 43 & 45 & 54 & 64 & 127 \\
\hline
\end{tabular}

D- Crystal size measured by XRD

$\mathrm{T}_{\text {mean }}$ size- Mean particle size measured by TEM

$\mathrm{B}_{\text {mean }}$ size- Mean particle size calculated using BET method. 


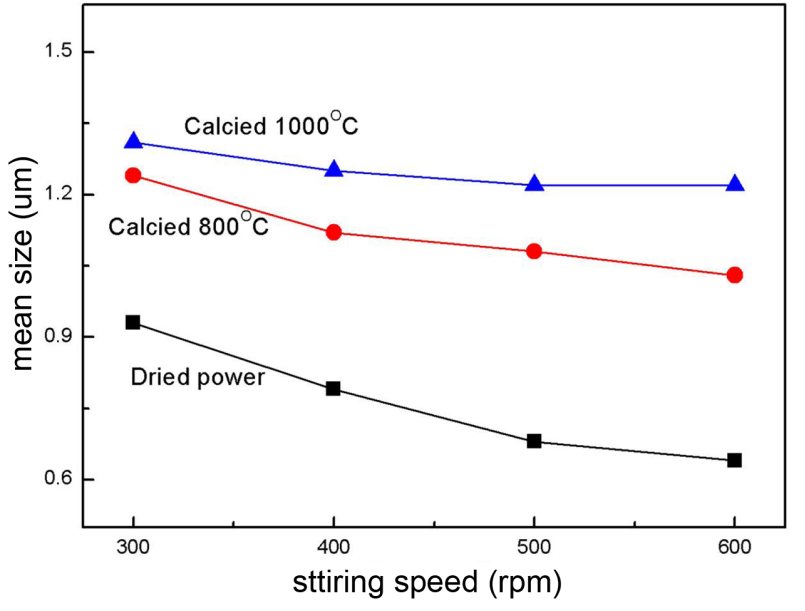

Fig. 4. Mean size of the aggregated particles as a function of stirring speeds and calcined temperatures.

sion frequencies among the produced particles will be increased as much, causing wear between particles due to collision and hence size diminution of final primary particles so that particle sizes may also be considered to be reduced as the stirring speed is increased. The fact that the width of reduction in mean sizes for the calcined particles compared with the particles after drying may be considered to indicate that the effects of calcination temperature are dominantly acting on aggregation in comparison with the factors in the synthesis stage as the preceding process.

\subsection{Particles as a function of calcination tempera- ture}

As synthesis and calcination temperatures among process temperatures exert a close influence on the primary particle sizes, XRD patterns of zirconia powders synthesized at 40 , 60 , and $80^{\circ} \mathrm{C}$, each synthesized product of which was then calcined at 600,800 , and $1000^{\circ} \mathrm{C}$, are shown in Fig. 5. Single-phase peaks of $8 \mathrm{YSZ}$ are being observed irrespective of synthesis and calcination temperatures, and it can be affirmed in general that the intensities of XRD peaks were increased and the half widths were narrowed down as the synthesis temperatures and the calcination temperatures were elevated. Particle sizes using XRD-LB method are shown in Table 2, which can be seen to be increased as the synthesis and the calcination temperatures are increased. In Fig. 6, microstructures were checked as a function of calcination temperature. As the calcination temperature was increased from $600^{\circ} \mathrm{C}$ to $1000^{\circ} \mathrm{C}$, the primary particle size can be affirmed to be increased from $10 \sim 20 \mathrm{~nm}$ to $30 \sim 60 \mathrm{~nm}$.

As with the primary particle size, the calcination temperature could also be seen to be involved in agglomeration. In Fig. 7, the analysis results of particle size for the zirconia powder synthesized at $60^{\circ} \mathrm{C}$ are shown as a function of the change in calcination temperatures. Amounts of the powder of $1 \sim 2 \mu \mathrm{m}$ in size due to the secondary agglomeration occurred in calcination process can be seen to be increased.
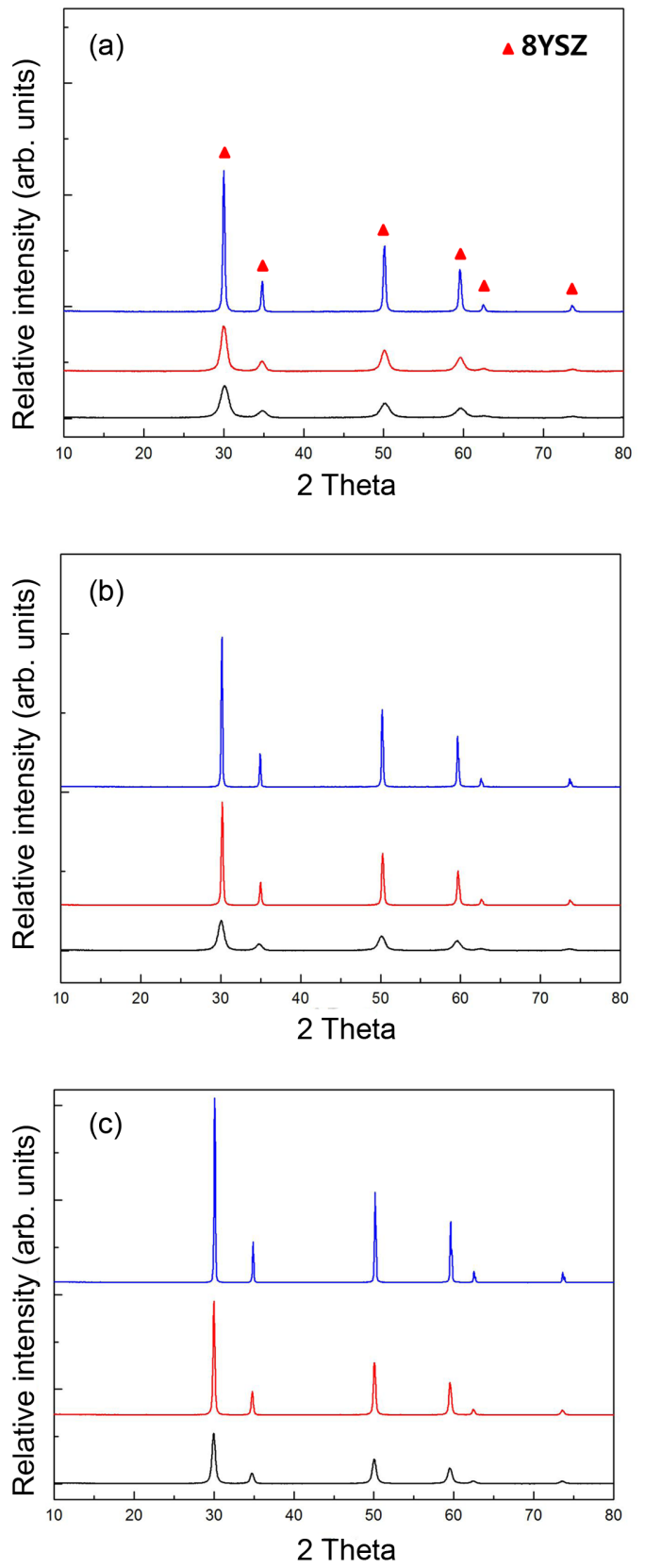

Fig. 5. XRD patterns of the calcined YSZ powders as a function of synthesis temperatures: (a) $40{ }^{\circ} \mathrm{C}$, (b) $60^{\circ} \mathrm{C}$, (c) $80^{\circ} \mathrm{C}$ (All powders were calcined at $600^{\circ} \mathrm{C}, 800^{\circ} \mathrm{C}$, and $1000^{\circ} \mathrm{C}$ for $4 \mathrm{~h}$ )

Table 2. Mean Particle Size of the 8YSZ Powders Obtained from Change in Calcination Temperatures as Measured by Different Techniques

Measurement $\quad 0.7 \mathrm{M}$ (co-precipitation Temp. $60^{\circ} \mathrm{C}$ )

$\begin{array}{lllll}\text { (Calcination Temperature) } & 600^{\circ} \mathrm{C} & 700^{\circ} \mathrm{C} & 800^{\circ} \mathrm{C} & 1000^{\circ} \mathrm{C}\end{array}$

\begin{tabular}{ccccc}
$\mathrm{D}(\mathrm{nm})$ & 11 & 25 & 38 & 59 \\
$\mathrm{~T}_{\text {mean }} \operatorname{size}(\mathrm{nm})$ & 16 & 22 & 37 & 52 \\
$\mathrm{~L}_{\text {mean }} \operatorname{size}(\mathrm{mm})$ & 0.99 & - & 1.12 & 1.31 \\
\hline
\end{tabular}

$\overline{\mathrm{L}_{\text {mean }} \text { size- Mean agglomerated particle size measured by laser }}$ scattering particle size distribution analyzer. 


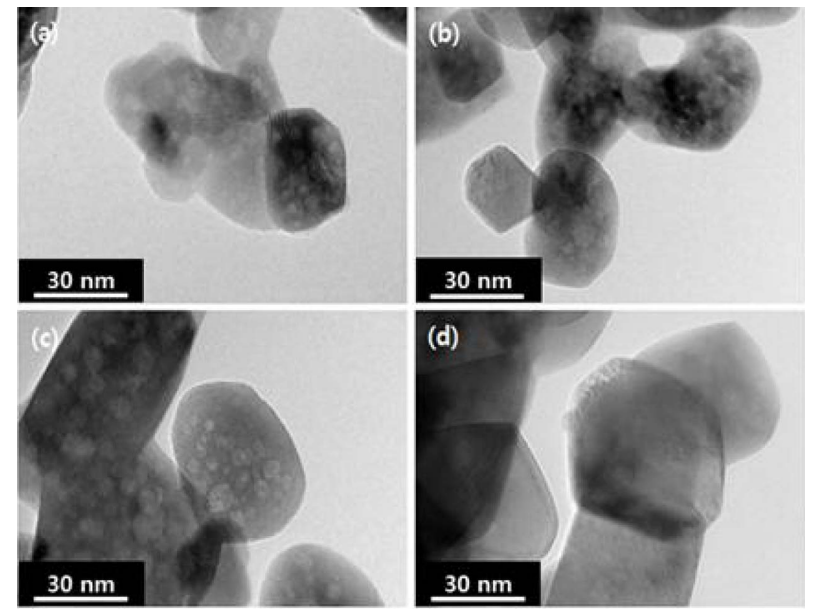

Fig. 6. TEM images of the YSZ powders as a function of calcination temperatures: (a) $600^{\circ} \mathrm{C}$, (b) $700^{\circ} \mathrm{C}$, (c) $800^{\circ} \mathrm{C}$, and (d) $1000^{\circ} \mathrm{C}$.

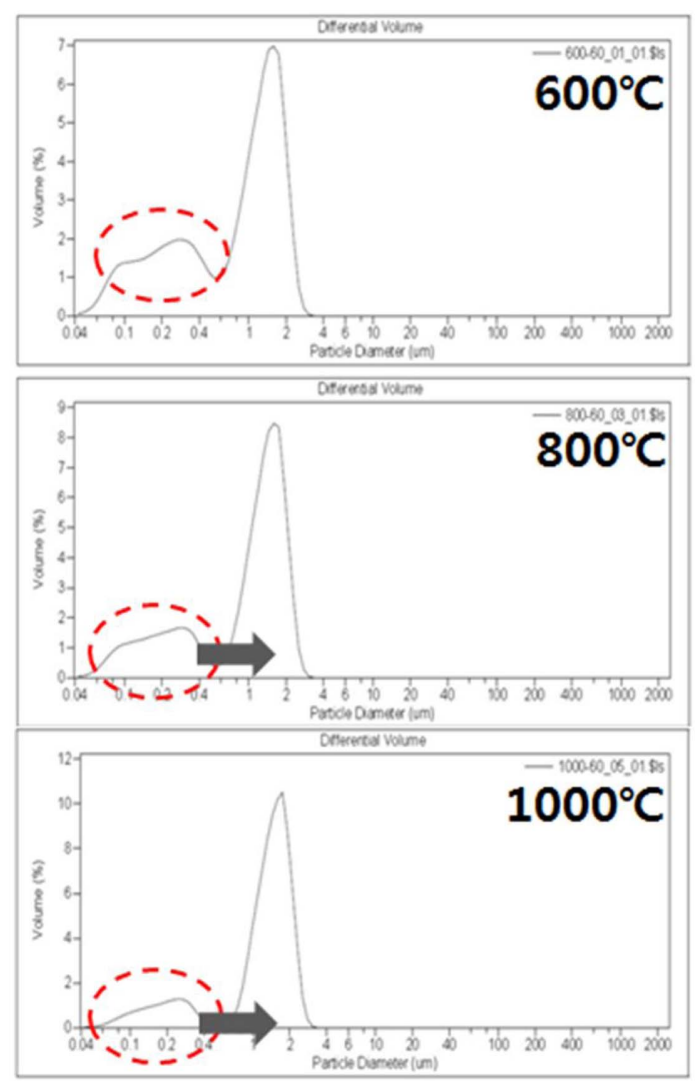

Fig. 7. Particle size distribution of YSZ powders as a function of calcination temperature.

mean particle sizes for the agglomeration shown in Table 2 were observed to be $0.99 \mu \mathrm{m}$ at $600^{\circ} \mathrm{C}$, and $1.32 \mu \mathrm{m}$ at $1000^{\circ} \mathrm{C}$.

\section{Conclusions}

In the present study, stabilized zirconia doped with $8 \mathrm{~mol} \%$ of yttria was prepared by using Modified Oxalate method, and the effects of reaction conditions such as temperature per process, concentration of reactants, and stirring speed, etc. on particle sizes and aggregation of the stabilized zirconia have been considered. Since particle growth due to aggregation drastically occurs above the concentration of 1.0 M for the starting raw material, the concentration condition of 0.7 $\mathrm{M}$ was affirmed to be appropriate to obtain zirconia powder having the size of $20 \sim 40 \mathrm{~nm}$. Synthesis and calcination temperatures had an effect on the primary particle size and the bonding forces for aggregation. According to the observation results with a TEM, the primary particle size was increased from $16 \mathrm{~nm}$ to $52 \mathrm{~nm}$ accompanied by an increase in the size of aggregates as the calcination temperature was increased from $600^{\circ} \mathrm{C}$ to $1000^{\circ} \mathrm{C}$. Lastly, as the stirring speed was increased, the cohesive forces between particles were reduced so that the size of powder after drying exhibited the minimum value of $0.64 \mu \mathrm{m}$ under the condition of $600 \mathrm{rpm}$.

\section{Acknowledgements}

This work was supported by the Technology Innovation Program (2015-0449, Technological development of a process for manufacturing high purity Zirconia and other application/products using zircon sand feed) funded by the Ministry of Trade, Industry \& Energy(Ml, Korea)

\section{REFERENCES}

1. S. Shukla and S. Seal, "Mechanisms of Room Temperature Metastable Tetragonal Phase Stabilisation in Zirconia," Int. Mater. Rev., 50 [1] 45-64 (2005).

2. N. Q. Minh, “Ceramic Fuel Cells," J. Am. Ceram. Soc., 76 [3] 563-88 (1993).

3. G. K Chuah, "An Investigation into the Preparation of High Surface Area Zirconia," Catal. Today, 49 [1] 131-39 (1999).

4. G. K. Chuah, S. Jaenicke, S. A. Cheong, and K. S. Chan, "The Influence of Preparation Conditions on the Surface Area of Zirconia," Appl. Catal., A, 145 [1] 267-84 (1996).

5. J. D. Kim, S. Hana, S. Kawagoe, K. Sasaki, and T. Hata, "Preparation of Perovskite, $\mathrm{Pb}(\mathrm{Zr}, \mathrm{Ti}) \mathrm{O}_{3}$ Thin-films on YSZ (111)/Si(111) Substrates by Post-Deposition Annealing," Thin Solid Films, 385 [1] 293-97 (2001).

6. M. Laurent, U. Schreiner, P. A. Langjahr, A. E. Glazounov, and M. J. Hoffman, "Microstructural and Electrical Characterization of La-doped PZT Ceramics Prepared by a Precursor Route," J. Eur. Ceram. Soc., 21 [10] 1495-98 (2001).

7. J. V. Herle, T. Horita, T. Kawada, N. Sakai, H. Yokokawa, and M Dokiya, "Oxalate Coprecipitation of Doped Ceria Powder for Tape Casting," Ceram. Int., 24 [3] 229-41 (1998).

8. T. S. Zhang, J. Ma, L. B. Kong, P. Hing, Y. J. Leng, S. H. Chan, and J. A. Kilner, "Sinterability and Ionic Conductivity of Coprecipitated $\mathrm{Ce}_{0.8} \mathrm{Gd}_{0.2} \mathrm{O}_{2}-\delta$ Powders Treated via a High-Energy Ball-Milling Process," J. Power Sources, 124 [1] 26-33 (2003). 
9. T. S. Zhang, P. Hing, H. Huang, and J. A. Kilner, "Ionic Conductivity in $\mathrm{CeO}_{2}-\mathrm{Gd}_{2} \mathrm{O}_{3}$ System $(0.05 \leq \mathrm{Gd} \leq 0.4)$ Prepared by Oxalate Coprecipitation," Solid State Ionics, 148 567-73 (2002).

10. R. S. Torrens, N. M. Sammes, and G. A. Tomsett, "Characterisation of $\left(\mathrm{CeO}_{2}\right)_{0.8}\left(\mathrm{GdO}_{1.5}\right)_{0.2}$ Synthesised Using Various Techniques," Solid State Ionics, 111 9-15 (1998).

11. K. Higashi, K. Sonoda, H. Ono, S. Sameshima, and Y. Horata, "Synthesis and Sintering of Rare-Earth-Doped
Ceria Powder by Oxalate Coprecipitation Method," $J$. Mater. Res., 14 [3] 957-67 (1999).

12. R. L. Coble, "Effects of Particle Size Distribution in Initial Stage Sintering," J. Am. Ceram. Soc., 56 [3] 461-66 (1973).

13. D. W. Johnson, D. J. Nitti, and L. Berrin, "High Purity Reactive Alumina Powders: II. Particle Size and Aggregation Study," Am. Ceram. Soc. Bull., 51 [12] 896-900 (1972).

14. R. G. Horn, "Surface Forces and their Action in Ceramic Materials,” J. Am. Ceram. Soc., 73 [5] 1117-35 (1990). 